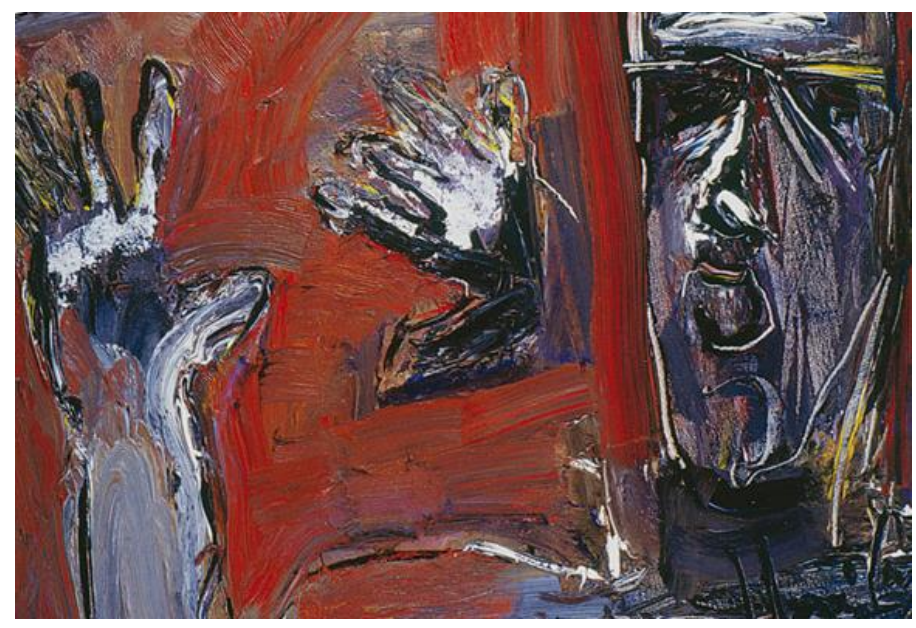

\title{
O gaúcho como herói da decadência em Os ratos, de Dyonélio Machado
}

The gaucho as an urban hero of decadence in Os ratos, by Dyonelio Machado

Ismael Sebben $^{1}$
https://orcid.org/0000-0001-5380-8992
Douglas Ceccagno ${ }^{2}$
https://orcid.org/0000-0001-9709-7854

Resumo: O objetivo deste artigo é identificar e analisar, na obra Os ratos, de Dyonélio Machado, com foco em seu protagonista Naziazeno Barbosa, a condição humana do homem citadino perante a Porto Alegre do início do século XX, ressaltando as transformações do mito do gaúcho herói, bem como explicitar os comportamentos daquele que se entende ser um herói da decadência. Para tanto, abordar-se-ão, a partir de textos teóricos que discorrem sobre a Porto Alegre da época, seu espaço e suas vivências, o imaginário das cidades, a relação entre campo e cidade na história e na literatura, além da caracterização do herói da decadência. Assim, com base na representação que os textos teóricos e literários oferecem e mediante a análise da obra de Dyonélio, visa-se a discorrer sobre a mutação do mito do gaúcho herói a partir das transformações do espaço, da subversão de valores e da imposição de novas normas de conduta a que é submetido Naziazeno no espaço urbano.

Palavras-chave: Os ratos; herói da decadência; gaúcho herói; mito.

Abstract: This essay aims at identifying and analysing, in the book Os ratos, by Dyonélio Machado, and focusing on its protagonist Naziazeno Barbosa, the human condition regarding the city of Porto Alegre in the early twentieth century, highlighting the transformation of the gaucho-hero myth, as well as explaining the behaviors of who's meant to be a hero of decadence. Therefore, we approach, from theoretical texts that discuss the Porto Alegre of that time, his space and his experience, the imaginary of the cities, the relationship between town and country in history and literature, as well as the characterization of the anti-hero. Thus, based on the representation that the theoretical and literary texts offer, and by analysing Dyonélio's work, we aim at discussing the gaucho-hero myth mutation from the changes in space, the subversion of values and the imposition of new rules of conduct to which Naziazeno is submitted in the urban space.

Keywords: Os ratos; hero of decadence; gaucho-hero; myth.

\footnotetext{
1 Graduado do Curso de Letras da Universidade de Caxias do Sul (UCS). E-mail: ismaelsebben@gmail.com.

${ }^{2}$ Doutor em Letras pela Pontifícia Universidade Católica do Rio Grande do Sul (PUC-RS); professor do Programa de Pós-graduação em Letras e Cultura da Universidade de Caxias do Sul (UCS). E-mail: dceccag1@ucs.br.
} 


\section{O mito do gaúcho e o herói da decadência naziazeno}

A temática urbana na literatura do Rio Grande do Sul ganhou força na década de 30, com o aumento da população da sua capital, Porto Alegre, decorrente da ampliação dos negócios e de oportunidades de emprego. A crise agropecuária também fez com que o gaúcho do pampa fosse submetido a vivenciar o urbano, ou seja, o que se deu foi uma crescente migração do campo para a cidade. Sendo assim, os ficcionistas gaúchos passaram a valorizar a "selva de pedra", buscando uma representação do espaço e das vivências urbanas e, por conseguinte, a renovação de um imaginário social. Partindo do pressuposto de que a migração do gaúcho de seu espaço habitual para a urbe ressignificou também o mito de origem, com base na representação que os textos teóricos e literários oferecem e mediante a análise de trechos da obra Os ratos, de Dyonélio Machado, investiga-se aqui, com foco em seu protagonista, Naziazeno Barbosa, este "gaúcho a pé"3, a condição humana do homem citadino da época, assim como a sua representatividade como herói da decadência.

Dyonélio Machado, em seu segundo livro, Os ratos, acompanha um dia na vida do funcionário público Naziazeno. O romance se passa na Porto Alegre do começo do século XX e é narrado em terceira pessoa por um narrador onisciente. Já nas primeiras páginas do livro, é informado ao leitor o problema que conduz a ação da personagem: Naziazeno deve 53 mil-réis ao leiteiro e, se não pagar a dívida, terá o fornecimento cortado. A partir desse momento, o protagonista embarca em uma verdadeira odisseia em busca do dinheiro para pagar o leiteiro, sendo que uma teia kafkiana o amarra, dificultando cada vez mais o sucesso de sua empreitada. Da mesma forma que em $O$ processo, de Kafka, quando, pela manhã, de súbito, Josef K. é acordado e preso sem saber o porquê, Naziazeno também acorda sem saber o que fazer, preso ao dilema de conseguir o valor necessário para saldar a dívida.

Seguindo as características que marcam o ideal regionalista do gaúcho, percebese uma discrepância muito grande entre o mito do gaúcho e Naziazeno. Em relação ao mito, pode-se dizer que é aquele que cria e dá exemplo, funda uma estrutura do real

\footnotetext{
${ }^{3}$ Essa expressão se aplica primeiramente à obra de Cyro Martins, que representou o êxodo da região da Campanha rio-grandense e a decadência do homem que sai do campo para a cidade. "Cyro Martins é o autor mais produtivo do período; grande parte de sua obra está dedicada à temática rural, e o autor considera Sem rumo, Porteira Fechada e Estrada nova uma trilogia, dedicada ao assunto do 'gaúcho a pé'. Este constituiria uma nova visão do herói tradicional dos pampas, apresentado no seu estado atual: de penúria econômica e desenraizamento social. Já que foi jogado para fora do campo, vivendo como um pária da sociedade urbana." (ZILBERMAN, 1982, p. 69)
} 
como um comportamento humano. Para Sandra J. Pesavento, o mito das origens, indo de encontro às necessidades do inconsciente coletivo, orienta e guia a percepção:

Todo ato fundador tende à sacralização. Assim, nascem os "mitos de origem", segundo a narrativa dos pósteros, articulando uma representação glamourizada dos acontecimentos que deram início a um processo que chega até nós. Na representação imaginária, ex-post, de um passado ao qual ninguém esteve presente, nasce o "mito" que com sua força criadora dá sentido, organiza, hierarquiza, seleciona e atribui valores de positividade para construir uma resposta à questão universal que todos indagam: de onde viemos? Da nação à cidade, o mito das origens articula os cacos da passeidade numa representação convincente e desejável que, ao mesmo tempo em que vai ao encontro das necessidades do inconsciente coletivo, orienta e guia a percepção. (PESAVENTO, 2002, p. 245)

O gaúcho mítico caracteriza-se pelo nomadismo, age sem rumo, portanto tem liberdade, busca a aventura, tem os olhos focados nas conquistas, nas guerras, procura, no seu íntimo, desbravar, como herói que considera ser; é forte e valente nas dificuldades. Além disso, segundo Guilhermino Cesar:

Gaúcho é sinônimo de homem do campo. Afeito a duras lidas, sobralhe tempo para conhecer a natureza que o rodeia [...].

Na cidade grande, o gaúcho conserva ainda um traço de inadaptação a rusticidade, que é um de seus encantos, uma das marcas dessa civilização naturalmente fraterna, sem atitudes constrangidas. (CESAR, 2006, p. 41-42)

Por isso, o gaúcho urbano deve ser tomado como um "nostálgico do campo." Ainda Pesavento atesta que o contexto militar fronteiriço é que iria reforçar e dar base à formulação da identidade regional: "Misto de saga e epopeia, o contexto militar fronteiriço iria fornecer referencial de contingência para a formulação de uma identidade regional, calcada nos valores da guerra, da honra, da bravura e construída em torno do seu personagem-símbolo, o gaúcho.” (2002, p. 247)

Já o protagonista de Os ratos é sedentário, também sem rumo, mas seu destino é causado pela competitividade do mundo moderno. Guerreia por obrigação, por estar submetido a uma decadência moral e financeira, na luta pela comida de todo dia. Carrega consigo a fraqueza, a vergonha e o desânimo, como neste trecho do romance em que Naziazeno mendiga por comida:

- O sr. não imagina o que tem sido ultimamente a minha vida... As dificuldades...

- Imagino.

- Hoje, aqui onde me vê - diz-lhe Naziazeno, numa confissão - ainda não almocei.

- Como?! Não tem o que comer?...

Um vermelhão cobre a cara de Naziazeno. 
- Não é isso - acrescenta ele, justificando-se: - tive de ficar na cidade... pra conduzir um negócio... Não pude voltar pra casa pra almoçar.

(Não diz: - "E não tive dinheiro pra almoçar na cidade".)

O outro ouve calado.

(MACHADO, 2004, p. 95-96)

Portanto, podemos considerar Naziazeno, por fugir aos padrões do mito gaúcho, um herói da decadência. Mas o que faz de Naziazeno este "gaúcho às avessas"? A cidade, a Porto Alegre do início do século XX. Em Memória Porto Alegre: espaços e vivências, Pesavento descreve essa Porto Alegre da seguinte forma:

A Porto Alegre das primeiras décadas do século XX já continha em si o drama das grandes cidades da época, sofrendo seus problemas locais: o trânsito de pedestres, carroças, carros e bondes em sua área central; os cuidados com o passeio público, com a coleta de lixo e matérias fecais, a implantação de sistemas de esgotos, de iluminação pública, de abastecimento d'água. (PESAVENTO, 1999, p. 59)

O autor de Os ratos utiliza-se dos aspectos que caracterizam as cidades, com seus problemas locais: "O semicírculo do horizonte que Naziazeno abraça com o olhar está pesado de vapores. O rio, que reflete e baralha as cores escuras e claras do céu, tem um movimento lento e espesso de óleo.” (MACHADO, 2004, p. 99)

Nas páginas seguintes, Dyonélio volta a referir-se ao céu pesado: “Aquele penacho de fumaça escura que se ergue meio dobrado sobre o céu pesado de vapores são as “obras”. A fumaça é da usina.” (MACHADO, 2004, p. 102)

Naziazeno não é o único personagem da literatura gaúcha a sofrer os males da cidade. Em Porteira fechada, de Cyro Martins, obra que faz parte da Trilogia do gaúcho a pé, o gaúcho fecha a porteira e sai, pobre e despilchado. João Guedes é a personagem que representa o homem que foge do campo em decorrência da crise agropecuária e que, na urbe, precisa sobreviver. Vira alcoólatra, rouba, vende seu cavalo, é preso, ganha a liberdade, mas perde a dignidade. A obra de Cyro Martins retrata a decadência do homem que sai do campo para a cidade; mas tanto a Trilogia do gaúcho a pé quanto Os ratos põem o gaúcho, o homem, em mutação, em transformação. João Guedes chegando na cidade, Naziazeno sobrevivendo nela. Ambas mostram a degradação do homem e o desligamento do mito de origem do gaúcho. Sobre esta migração campo-cidade, Pesavento diz:

O aumento da população de Porto Alegre deveu-se, muito provavelmente, ao complexo desenvolvimento colonial imigrante que fizera da capital do estado o núcleo escoador de produtos que eram 
exportados para o centro do país. A ampliação dos negócios e das oportunidades de emprego converteu a cidade num pólo de atração da zona colonial, implicando uma certa migração campo-cidade. (PESAVENTO, 2002, p. 263)

Pesavento ainda acrescenta que "o êxodo rural se acentua no pós-30, surge a figura do "gaúcho a pé", do proletariado do pampa, mão-de-obra sem especialização que vai se marginalizar nas cidades.” (1980, p. 85)

Desta forma, a busca pela representação do espaço e das vivências instigaram escritores. Mas, mais do que isso, por trás do que está escrito, do véu que cobre a cidade, há a morada do questionamento, como afirma Pesavento: "A cidade não é simplesmente um fato, um dado colocado pela concretude da vida, mas, como objeto de análise e tema de reflexão, ela é construída como desafio e, como tal, objeto de questionamento.” (2002, p. 10) Dessa forma, a cidade, como cenário, tornou-se objeto de desejo dos escritores. Segundo Raymond Williams, a imagem da cidade passou a ser dominante na obra de alguns autores:

\begin{abstract}
$\mathrm{Na}$ literatura mundial, em Balzac, Baudelaire e, de maneira diferente, Dostoiévski, a imagem da cidade tornou-se, de certo modo, dominante. Balzac havia demonstrado a complexidade social da cidade e sua mobilidade constante; como seu objetivo era justamente descrever este aspecto, a imagem resultante, embora complexa, é clara. Dostoiévski, por outro lado, enfatizava os elementos de mistério e estranheza e perda de conexão; de modo comparável Dickens, porém partindo de reações fundamentalmente diferentes, trabalhava no sentido de criar reconhecimentos. Ele difere de Dickens na medida em que a fonte de reconhecimento não reside numa consciência social sufocada, e sim num reconhecimento espiritual, situado além do desespero do isolamento. Baudelaire, por sua vez, inverteu ambos esses valores. $\mathrm{O}$ isolamento e a perda de conexão passaram a ser as condições de uma nova e viva percepção. (WILLIAMS, 2000, p. 315)
\end{abstract}

A partir disso, entende-se que o escritor é aquele que vê com os olhos das suas personagens, colocando-se no lugar dessas, mas também aquele que expressa sua visão a partir da sua criação. Para Sandra J. Pesavento, o escritor, ao olhar a cidade, cria a cidade do pensamento, traduzida em palavras e imagens; e, sendo o olhar aquele que qualifica o mundo, a partir da narrativa literária ordena-se o real e a ele é conferido um valor, portanto o que se exerce é uma espécie de "pedagogia da imaginação". (PESAVENTO, 2002, p. 10)

Em Os ratos, a paisagem já não mostra o campo, o horizonte e, sobretudo, o cavalo, símbolo de companheirismo do gaúcho. Como afirma Regina Zilberman, referindo-se ao gaúcho, ele: “[...] integra-se a uma ordem natural, na medida em que 
tem afinidades com o espaço - o pampa, a Campanha - e que são os animais, sobretudo o cavalo, seus maiores companheiros." (1982, p. 36)

Os olhos batem nos prédios, percorrem ruas, placas, acompanham pernas e pessoas, o gaúcho agora está em um bonde, não mais em um cavalo: “O bonde, que desliza numa corrida vertiginosa, para de súbito, travado com força. Há um meio de tumulto dentro do veículo, com os passageiros lançados para a frente, os bancos desarticulando-se." (MACHADO, 2004, p. 19).

O ambiente urbano em que está inserido também mexerá com os pensamentos do herói da decadência. É a vida corrida que faz “a cabeça não parar”, é o suor o líquido que faz a engrenagem girar. Sendo assim, pode-se dizer que o protagonista mais pensa do que fala. A solidão de Naziazeno, na cidade, dentro de um bonde lotado, comparada à do gaúcho percorrendo o campo com seu cavalo, parece ser ainda maior. Em O campo e a cidade na história e na literatura, Raymond Williams faz uma importante observação em relação às associações atribuídas ao campo e à cidade:

\begin{abstract}
Em torno das comunidades existentes, historicamente bastante variadas cristalizaram-se e generalizaram-se atitudes emocionais poderosas. O campo passou a ser associado a uma forma natural de vida - de paz, inocência e virtudes simples. À cidade associou-se a ideia de centro de realizações - de saber, comunicações, luz. Também constelaram-se poderosas associações negativas: a cidade como lugar de barulho, mundanidade e ambição; o campo como lugar de atraso, ignorância e limitação. O contraste entre campo e cidade, enquanto formas de vida fundamentais, remonta à Antiguidade clássica. (WILLIAMS, 2000, p. 11)
\end{abstract}

A verdade é que o protagonista de Os ratos, no frenesi da cidade, não descansa a cabeça. Portanto, é de suma importância a estratégia narrativa que o autor utiliza na obra, com um narrador onisciente mostrando-nos o que pensa Naziazeno Barbosa. Como neste trecho, em que os estímulos exteriores perturbam seu interior, lembrando-o incessantemente de sua dívida com o leiteiro:

Dorso redondo de passageiro descendo do bonde - traço claro de dorso riscando o ar na "escadinha": o leiteiro!

A placa (a conhecida placa) no consultório do entroncamento- "Tu ainda não pagaste o doutor, Naziazeno" - o leiteiro!

Ideia de desembarcar no mercado, imagem do Duque rodando o caféo leiteiro... o leiteiro... (MACHADO, 2004, p. 20-21, gr. orig.)

Mas se as ruas o atordoam, dentro de casa também sua mulher faz com que Naziazeno reflita. É ela reflexo da sua miséria, nas palavras do narrador "uma confissão pública de miséria humilhada, sem dignidade" por "atarantar-se, perder-se, empalidecer". É a partir do comportamento dela que Naziazeno reflete sobre seus atos: 
Ele precisa de um ser forte a seu lado. Toda a sua decisão se dilui quando vê junto de si, como nessa manhã, a mulher atarantar-se, perder-se, empalidecer. É o primeiro julgamento que ele recebe; a primeira censura aos seus atos, os quais começam, pois, por the parecerem irregulares, ilícitos. Sentir-se-ia fortificado, ou ao menos "justificado", se visse ao seu lado a mulher do amanuense franzindo a cara ao leiteiro, pedindo-lhe para repetir o que houvesse dito, perguntando-lhe o que é que estaria porventura pensando deles. A sua mulher encolhida e apavorada é uma confissão pública de miséria humilhada, sem dignidade - da sua miséria. (MACHADO, 2004, p. 19).

Em Os ratos, a figura da mulher submissa ao marido não se configura; ela toma outra forma: a de derrotada por conta da fraqueza masculina, daquele que deveria ser "o homem da casa", que deveria sustentar o lar. Também não há uma exaltação da mulher, mas uma comparação com as demais. A fraqueza da mulher envergonha Naziazeno e o denuncia aos outros, caracterizando-o como miserável. A mulher, Adelaide, por sua vez, também compara o marido a outros; por exemplo, no trecho em que questiona o porquê de o marido não procurar um biscate: “- Eu sei que há muitos homens que arranjam um biscate depois que largam o serviço" - dissera-lhe uma vez a mulher. "- Por que não consegues um pra ti?”. (MACHADO, 2004, p. 44)

Só próximo do fim do romance é que Adelaide esboça um sorriso, certa alegria, e é por conta da comida em cima da mesa, mostrando ser o dinheiro também aquele que rege as relações pessoais em um espaço urbano, capitalista e cada vez mais competitivo: “- Tu trouxeste manteiga? A face da mulher enche-se dum leve rubor. É um rubor que lhe sobe o pescoço e que a remoça - rubor de rapariga..." (MACHADO, 2004, p. 144)

Só quando Naziazeno tem o dinheiro em mãos é que consegue sorrir e sentar tranquilo na cadeirinha de balanço, mas isso por pouco tempo. Ou seja, em Os ratos há uma supervalorização do dinheiro. Segundo Raymond Williams, a associação entre cidade e dinheiro sempre deixou marcas na história:

Por exemplo, temos de observar que a cidade está associada, nos século XVI e XVII, ao dinheiro e à lei, e, no século XVIII, à riqueza e ao luxo; que há uma associação persistente, chegando ao auge no final do século XVIII e no XIX, à imagem da turba, das massas; que, nos séculos XIX e XX, a cidade é associada à mobilidade e ao isolamento. Cada uma dessas ideias tem uma certa persistência, mas o isolamento, por exemplo, só aparece como tema importante durante a fase de desenvolvimento metropolitano, enquanto a associação entre cidade e dinheiro vai desde a constatação de atos isolados de corrupção e intriga até a visão de um sistema comercial e político. (WILLIAMS, 2000, p. 388) 
Percebe-se então um tema universal: a busca pelo dinheiro, condição primordial de Naziazeno. Ainda fazendo referência ao poder aquisitivo e ao estrato social, segundo Flávio R. Kothe, personagens proletárias têm ganhado espaço nos romances modernos, diferente, por exemplo, de obras clássicas antigas, onde as personagens eram geralmente aristocratas (KOTHE, 1987, p. 66). Dyonélio Machado, através de Naziazeno Barbosa, dá voz a uma classe menos favorecida, a do proletariado. Veem-se também no romance, as condições dos operários a partir da voz do narrador:

O dia terminou ali. Os operários lá nas "obras" estão "largando" cada um com sua latinha de comida. Vão disciplinarmente à guarita do seu Júlio, pra ser passada a revista. Todos aqueles podiam ser ladrões... O seu Júlio não acredita... nem desacredita: ele revista apenas. É uma obrigação que uns e outros têm... (MACHADO, 2004, p. 95-96)

Kothe ainda comenta sobre o uso, em romances do passado, de personagens heroicas aristocráticas e a tendência de os agrupamentos marginais servirem apenas à alegoria. Naziazeno é, pois, de outra linhagem, da cria moderna: personagem que ganha significado na obra, um herói proletariado que, portanto, incorpora os problemas da classe trabalhadora, em vez das trivialidades aristocráticas. Pondo olhos na personagem Naziazeno, percebe-se que ele pertence a um estrato social baixo e se torna o centro da narrativa com o dilema de angariar a quantia necessária para amortizar a dívida com o leiteiro. Sua busca pelo dinheiro se dá sem heroísmo, embora ele tenha dificuldades para obtê-lo.

\section{Naziazeno: o herói da decadência}

No romance de Dyonélio Machado, diferentemente de outras obras em que se pode reconhecer a figura do gaúcho-herói, temos uma personagem configurada como herói da decadência, que, no desespero de solucionar seu problema, busca a jogatina, pede dinheiro, mendiga comida e, em determinadas partes da história, desanima. Analisando o que diz Flávio R. Kothe em $O$ herói, podemos encaixar Naziazeno na classe dos heróis da decadência, característica dos heróis contemporâneos contrários à trivialidade: "Quando há heróis positivos e felicidade, a poética moderna aponta normativamente para a trivialidade.” (KOTHE, 1987, p. 62) Já não temos um herói guerreiro, imbatível, mesmo tendo ele saído vencedor naquele dia, mas uma personagem esmagada pela condição financeira e pelo estado psicológico em que se 
encontra. Já no romance de Dyonélio, o gaúcho, representado pelo protagonista, envergonha-se de sua condição:

Naziazeno resolve não deixar passar aquela oportunidade:

- Você não terá aí uns dez mil-réis que me ceda até amanhã? Ainda não almocei. (Esta última frase fica-lhe retumbando no ouvido. Ele sente um calor em toda a cara.). (MACHADO, 2004, p. 75)

O que se percebe é que Naziazeno, embora constrangido, ainda assim não vê outra saída senão a de pedir dinheiro emprestado para o almoço, ou seja, é a condição que o transforma, já que ele não consegue transformar, por si só, com suas próprias forças, a situação, tendo que esperar que alguém lhe estenda as mãos. Segundo Sandra J. Pesavento, a urbanização, dentre outras coisas, tende a transfigurar o homem citadino. Quanto a isso, cita Balzac, aquele que de forma bela e exaustiva construiu o imaginário social de uma das cidades mais representadas do mundo:

Estaria Balzac, com suas fisionomias parisienses, estabelecendo o tipo ideal do homem citadino moderno? Conquistador e sedutor, inescrupuloso e amoral, esse é o perfil do herói moderno das novas metrópoles. A urbanização desfaz costumes e subverte valores, estabelecendo novas regras de conduta. (PESAVENTO, 2002, p. 67)

Assim, a partir da atitude tomada pelo protagonista de $O s$ ratos - não querendo perder a oportunidade de pedir o dinheiro - e a culpa retumbando em seus ouvidos prova da vergonha sentida por mendigar - fica claro que Naziazeno sente-se confuso e impotente em relação a sua situação: sem dinheiro e com fome. Um dos trechos do livro em que é evidente que a personagem principal não entende a sua condição e não a aceita é na hora em que passa em frente ao brique, e vê, nos fundos da loja, o dono. Tem-se, nesta parte do romance, a comparação entre a situação do dono do brique, sereno e indiferente ao ganho, e a de Naziazeno, na ânsia de angariar o valor para pagar o leiteiro:

Essa espada em diagonal na vitrina do brique já está aí há muito tempo. O homem do brique vive dum comércio calmo. De tempo em tempo um freguês, que discute muito, examina muito, regateia. $\mathrm{O}$ homem do brique é sereno, parece indiferente ao ganho, e como que se consola igualmente com o vender ou o não vender. Mas ele não compreende!... Porque há aluguel da casa, o armazém, o pão, o leite... tudo, entretanto, aí parece regulado, uma fatalidade, complacente zelando para que tudo se equilibre, se equilibre o ganho e o gasto, se equilibre a vida...

E o homem do brique, sentado lá no fundo, num recanto mais escuro, com o cachimbo na boca, olhando firme a porta, aparece-lhe bem como esse homem médio, invejável e bronco... (MACHADO, 2004, p. 48). 
Outra característica importante que se deve mencionar sobre Naziazeno é a distinção entre o real e o imaginário. Por vezes o protagonista troca o real pela suposição, articula planos na cabeça, anima-se e desanima-se, porém o que o condiciona, o configura como ser, é a realidade em que vive, e assim não põe em prática o que pensa. Naziazeno é obra, não de suas vontades, mas do seu meio:

Já se lhe foram quinhentos réis...- Um medo o invade, então! Mas é passageiro, e outra vez está ali com ele a sua confiança.

"- Doutor, vejo-me outra vez forçado a recorrer..." - Não! Isto é vago, geral. Deve dizer o fato, o que se passa. "- Doutor, imagine a minha situação, o meu leiteiro...” - Não! Não! Trivialidade... uma trivialidade... "O meu filho, doutor!..." - Outra vez o teu filho, Naziazeno... sempre o teu filho...

Um gelo toma todo o seu corpo. Gelo que é tristeza e desânimo. Voltam-lhe as cenas da manhã, o arrabalde, a casa, a mulher. (MACHADO, 2004, p. 26- 27, grifos originais).

Nessa perspectiva, percebe-se como característica da personagem a evasão da realidade, por conta de uma realidade inventada que o conforta e que, ao mesmo tempo, o destrói.

\section{A roleta e os dias na cidade}

Naziazeno é seduzido pelo jogo, pela roleta. E arrisca-se, encontrando a sorte em um número. No entanto, entre perdas e ganhos, o protagonista termina sem um mísero trocado. O cíclico da roleta e do jogo remete-nos a pensar em Sísifo e sua interminável tarefa de ter que levar a pedra até o topo de uma montanha, para depois, quando já está quase no cume, vê-la rolar novamente para, de forma inútil, ter que seguir seu trabalho. Assim como a pedra, a roleta, que o ilude, faz de Naziazeno vencedor uma vez, mas no final the tira o que havia lhe dado. Um dia o faz vencedor, porém outro virá. Será que a sorte o premiará novamente? Levando em consideração a característica atribuída a Balzac por Pesavento, estaria Dyonélio querendo também estabelecer o tipo ideal do homem citadino moderno de Porto Alegre? Talvez um dos tipos, levando em conta a extensa produção de Balzac em proporção à de Dyonélio e à de tantos outros escritores. Também Pesavento, e agora temos um dado que aproxima as cidades, cita Paris como cidade modelo para os planos de construção da Porto Alegre do início do século XIX, liderados pelo engenheiro José Montaury de Aguiar Leitão, intendente escolhido por Júlio de Castilhos, então governador do estado: 
Nos planos das representações, a cidade-ideal dos gaúchos precisava encontrar formulações locais que estabelecessem um caminho em face de uma dupla mediação: por um lado, havia o modelo parisiense, conhecido da sua elite cultivada, reforçado pela matriz positivista e paradigma consagrado de modernidade urbana. Mas por outro lado, os projetos da cidade-ideal iriam encontrar, nas primeiras décadas do século, dois exemplos americanos de que tal aventura era possível, do outro lado do oceano: Rio de Janeiro e Buenos Aires. (PESAVENTO, 2002, p. 271)

Verdade é que, seja na cidade pequena, seja na metrópole, as pessoas vão às ruas, passeiam levando consigo suas hierarquias e costumes; desfilam olhares uns aos outros com bondade ou raiva, criam a imagem real da diversidade e, a par de tudo isso, a cidade vai sendo moldada.

Assim também, de acordo com o que sugere Dyonélio Machado, permanecerão os dias de sobrevivência de Naziazeno: cíclicos. Na parte final do romance, quando a personagem, na ânsia de entregar o dinheiro ao leiteiro, preocupada com o dia seguinte e sem sono, ouve ou imagina os ratos roendo seu dinheiro, evidencia-se que o autor procura informar ao leitor que outro dia virá e, novamente, ele, o herói da decadência, terá que desprender-se das dificuldades. Segundo Regina Zilberman, estas 24 horas servem ao leitor como exemplo, para que sejam imaginados os demais dias da vida de Naziazeno:

É tal a exemplaridade que acentua o aspecto angustiante de seu percurso diário: pois, se todos os dias são como este, sua existência converte-se num estafante, interminável e improdutivo exercício voltado a tapar as lacunas criadas pela sua condição de um exilado da vida, alienado em relação a um fluxo temporal que não consegue acompanhar devido exclusivamente à sua crise pecuniária. (ZILBERMAN, 1982, p. 76)

Dessa forma, o que se percebe é que a busca pelo dinheiro se torna sua situação existencial. Naziazeno Barbosa é um homem que vive para o hoje, que guerreia dia a dia pelo pão. É o herói da decadência, mutação do mito tradicional, exemplo do que nos diz Pozenato:

$\mathrm{O}$ mito deixou de ser o centro de unidade do fazer para permear difusamente todo o viver cotidiano. Talvez a memória dele, guardada pela gauchesca, ajude a localizar sua fonte imaginária. Na linha das considerações aqui conduzidas, talvez se pudesse dizer que a "gauchidade" esteja na vontade da eficácia de fazer. Mas o mito, descontextualizando-se, fragmentou-se. É desses fragmentos, que trazem a marca do específico regional, que se pode afirmar serem os traços peculiares a estigmatizar uma sociedade que se abre para um horizonte universalizado. (POZENATO, 1974, p. 60) 
Portanto, observando algumas características do protagonista da obra e o lugar do espaço urbano da Porto Alegre do início do século XX, conclui-se que Naziazeno foge às características do mito gaúcho, carregando consigo o desânimo, a fraqueza, a vergonha, dentre outras discrepâncias em relação ao mito de origem, além de demonstrar, no decorrer desta odisseia em busca do dinheiro para saldar a dívida, desvios de conduta impostos contra a sua vontade pelo meio, males da cidade sentidos por este "gaúcho a pé" que tenta sobreviver na urbanidade.

\section{Referências}

CESAR, Guilhermino. História da literatura do Rio Grande do Sul (1737-1902). 3. ed. Porto Alegre: IEL; Corag, 2006.

KOTHE, Flávio R. O herói. 2. ed. São Paulo: Editora Ática S.A, 1987.

MACHADO, Dyonélio. Os ratos. 3. ed. São Paulo: Editora Planeta do Brasil, 2004.

PESAVENTO, Sandra J. Historiografia e ideologia. In: FREITAS, Décio et al. RS: cultura e ideologia. DACANAL, José H.; GONZAGA, Sergius (Org.). Porto Alegre: Mercado Aberto, 1980. (Série Documenta; 3)

PESAVENTO, Sandra J. Memória Porto Alegre: espaço e vivências. 2.ed. Porto Alegre: Ed. Universidade/ UFRGS, 1999.

PESAVENTO, Sandra J. O imaginário da cidade: visões literárias do urbano - Paris, Rio de Janeiro, Porto Alegre. 2. ed. Porto Alegre: Ed. Universidade/UFRGS, 2002.

POZZENATO, José Clemente. O regional e o universal na Literatura Gaúcha. Porto Alegre: Movimento, Instituto Estadual do Livro, 1974.

WILLIAMS, Raymond. O campo e a cidade na história e na literatura. São Paulo: Companhia das Letras, 2000.

ZILBERMAN, Regina. A literatura no Rio Grande do Sul. 2. ed. Porto Alegre: Mercado Aberto, 1982. 


\section{Para citar essa obra:}

SEBBEN, Ismael; CECCAGNO, Douglas. O gaúcho como anti-herói urbano em Os Ratos, de Dyonélio Machado. In: RUA [online]. Volume 24, número 2 - p. 449-460 e-ISSN 2179-9911 - novembro/2018. Consultada no Portal Labeurb - Revista do Laboratório de Estudos Urbanos do Núcleo de Desenvolvimento da Criatividade.

http://www.labeurb.unicamp.br/rua/

Capa: Detalhe da capa do livro Os Ratos, de Dyonélio Machado. Disponível em: https://pladlivrosbr8.cdnstatics.com/usuaris/libros/fotos/168/m_libros/os-ratos-2edicao_9788576655459.jpg

\section{Laboratório de Estudos Urbanos - LABEURB}

Núcleo de Desenvolvimento da Criatividade - NUDECRI

Universidade Estadual de Campinas - UNICAMP

http://www.labeurb.unicamp.br/

\section{Endereço:}

LABEURB - LABORATÓRIO DE ESTUDOS URBANOS

UNICAMP/COCEN / NUDECRI

CAIXA POSTAL 6166

Campinas/SP - Brasil

CEP 13083-892

Fone/ Fax: (19) 3521-7900

Contato: http://www.labeurb.unicamp.br/contato 